\title{
Superior Formation of Cortical Memory Traces for Melodic Patterns in Musicians
}

\author{
Mari Tervaniemi, ${ }^{1,2,3}$ Mika Rytkönen, ${ }^{1}$ Erich Schröger, ${ }^{4}$ Risto J. Ilmoniemi, ${ }^{1,5}$ and \\ Risto Näätänen ${ }^{1,5}$ \\ ${ }^{1}$ Cognitive Brain Research Unit, Department of Psychology, University of Helsinki, 00014 Helsinki, Finland; ${ }^{2}$ Department of Psychology, \\ University of Jyväskylä, 40351 Jyväskylä, Finland; ${ }^{4}$ Department of General Psychology, University of Leipzig, 04103 Leipzig, Germany; \\ ${ }^{5}$ BioMag Laboratory, Medical Engineering Centre, Helsinki University Central Hospital, 00029 HUS Helsinki, Finland
}

\begin{abstract}
The human central auditory system has a remarkable ability to establish memory traces for invariant features in the acoustic environment despite continual acoustic variations in the sounds heard. By recording the memory-related mismatch negativity (MMN) component of the auditory electric and magnetic brain responses as well as behavioral performance, we investigated how subjects learn to discriminate changes in a melodic pattern presented at several frequency levels. In addition, we explored whether musical expertise facilitates this learning. Our data show that especially musicians who perform music primarily without a score learn easily to detect contour changes in a melodic pattern presented at variable frequency levels. After learning, their auditory cortex detects these changes even when their attention is directed away from the sounds. The present results thus show that, after perceptual learning during attentive listening has taken place, changes in a highly complex auditory pattern can be detected automatically by the human auditory cortex and, further, that this process is facilitated by musical expertise.
\end{abstract}

For correct interpretation of natural acoustic input such as speech and music, it is of critical importance that the central auditory system is able to extract invariant features from the continually varying sounds. Spoken, played, and sung phrases are recognized even though they are presented by a great variety of speakers, instruments, or singers in different acoustic environments. Moreover, even when no conscious attention is paid to the surrounding sounds, changes in their regularity can cause the listener to redirect his or her attention toward the sounds.

During the past two decades, event-related potential (ERP) recordings have brought new insight to the neuronal events behind auditory change detection in audition. Components $\mathrm{P} 300, \mathrm{~N} 400$, and P600 (named after their negative/ positive polarity at the vertex and peak latency after the sound onset) are elicited when the subject attends to the sounds. These components reflect the conscious detection of a physical, semantic, or syntactic deviation from the expected sound (for review, see Rugg and Coles 1995). However, in group-comparison designs, intrinsic group differences in motivational, attentional and/or vigilance factors might contaminate the ERP recordings.

In addition, ERP recordings allow one to probe the neural processes preceding the involvement of the attentional mechanisms. In such studies, the subject is

${ }^{3}$ Corresponding author.

E-MAIL mari.tervaniemi@helsinki.fi; FAX 358-9-1912-2924.

Article and publication are at http://www.learnmem.org/cgi/doi/ 10.1101/lm.39501. asked to concentrate on a task unrelated to the sounds heard. These studies have revealed that automaticallyformed cortical memory traces for the recent acoustic input represent basic sound features such as tone frequency and the formant structure of speech sounds (for reviews, see Näätänen 1992, 2001). In addition, ERPs have been recorded that reflect memory traces representing sounds composed of several simultaneous or successive tonal elements (Schröger et al. 1992; Alain et al. 1994; Alho et al. 1996).

The results described above were obtained with the mismatch negativity (MMN) paradigm, in which an infrequently presented sound ("deviant") among the frequently occurring stimuli ("standard") elicits the MMN. Its presence implies that the invariant parameters of the standard sound were encoded neurally and found to differ from the parameters of the deviant sound. The MMN can be recorded even when the subject is performing a task unrelated to the stimulation under interest, such as reading a book or playing a computer game. Thus, the MMN offers a direct measure of the similarity of neural codes for different sounds, without being affected by differences in, for instance, attentional or motivational involvement of the subject. However, several studies have indicated that the MMN parameters correlate closely with the subject's behaviorally determined perceptual accuracy. For instance, the MMN amplitude and latency reflect discrimination accuracy as determined by musicality tests; Tervaniemi et al. 1997) and by hit-rate or reaction-time measurements (e.g., Tiitinen et al. 1994;

LEARNING \& MEMORY 8:295-300 @ 2001 by Cold Spring Harbor Laboratory Press ISSN1072-0502/01 \$5.00

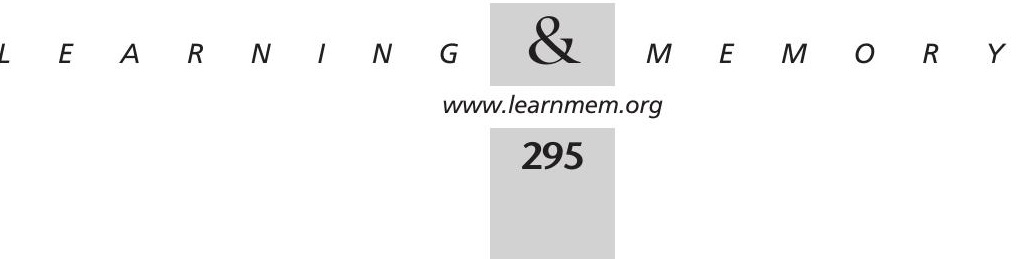


Kraus et al. 1996; Tremblay et al. 1998; Menning et al. 2000). This correlation between the MMN parameters and behavioral responses implies that pre-attentive processes determine the accuracy of the subsequent conscious processes (Novak et al. 1990; Näätänen 1992; Tiitinen et al. 1994; Näätänen and Winkler 1999).

A question of central importance involves the capacity of the nervous system to extract pre-attentively invariances in the acoustic input. Several studies showed that these invariances may be extracted from a sequence of variable sounds in which a feature or relationship between successive or parallel sounds remains constant (Saarinen et al. 1992; Tervaniemi et al. 1994; Paavilainen et al. 1998, 1999; Wolff and Schröger, 2001). For example, Saarinen et al. (1992) demonstrated that rarely occurring reversals of the direction of the otherwise constant frequency relation between two tones in a tone pair (ascending or descending) elicit MMN independently of the absolute frequencies of the tones. Consistent with this, Wolff and Schröger (2001) showed that, when tones of varying frequency are presented rapidly, even rare frequency repetitions elicit an MMN. However, stimulation employed in these studies has been relatively limited in the degree of abstractness when compared with that of natural speech or music.

A subsequent question in the present context is whether training may modify the pre-attentive encoding of invariances. It has been shown that the extraction of invariant features in auditory stimulation may benefit from previous training on a time scale of minutes, hours, and even years (cf. Schröger 2000). The effects of short-term training on invariance extraction were demonstrated by Näätänen et al. (1993) in a study in which a sound pattern consisting of 8 short tones was presented repeatedly to subjects not paying attention to the sounds. Initially, infrequent deviant patterns elicited no MMN. However, when subjects were trained to discriminate behaviorally the deviant patterns from the standard, they elicited an MMN even when they did not pay attention to the sounds. This result indicates the development of a memory trace for the sound pattern during active listening during one experimental session. This memory trace can then be activated in passive listening situations as well. The effect of expertise on a much longer time scale has been shown by Koelsch et al. (1999). In their study, professional violinists and non-musicians were presented with a frequent standard perfect major chord and an infrequent deviant chord. Even when the stimuli were ignored, the deviant chords elicited a distinct MMN in experts whereas no MMN was elicited in novices. This result reflects an improved ability in musicians to pre-attentively encode the invariant features of musically relevant input. Consequently, in active conditions, violinists were more accurate than non-musicians in discriminating between deviant and standard chords.

The goal of the present study was to determine whether active learning of abstract rules between successive tones in melodic patterns modifies the pre-attentive encoding of invariances as indexed by the MMN. Moreover, the study took into account two types of learning, shortterm learning during an experimental session and long-term expertise in music.

The experiment consisted of Ignore and Attend conditions, which were presented to the subjects three times in alternating order. Stimulation throughout the experiment employed short melody-like sound patterns, which were presented at 12 different frequency levels. The majority of the patterns, the "standards," had a melodic contour of an inverted U, whereas $10 \%$ of the patterns, the "deviants," had a different contour. In the Attend conditions, the subjects were instructed to detect the patterns with deviant contour. In the Ignore conditions they watched a self-selected silent movie. Out of the 20 subjects, 13 were musicians.

\section{RESULTS}

The subjects were divided into two groups on the basis of their behavioral performance in the Attend conditions. The eight Accurate subjects had a hit rate of $91 \pm 9 \%(88 \pm 9 \%$, $93 \pm 7 \%, 91 \pm 10 \%$ in the first, second, and third Attend conditions, respectively; the mean across the conditions was at least $85 \%$; false-alarm rate $0.3 \%$ ). The 12 Inaccurate subjects had a hit rate of $41 \pm 26 \%(38 \pm 26 \%, 40 \pm 23 \%$, and $46 \pm 29 \%$; the mean across the conditions was not higher than $71 \%$; false-alarm rate $<1 \%$ ).

During the first Ignore condition, the brain responses to standard and deviant melodic patterns did not differ statistically significantly from each other in either group (Fig. 1). However, in the Ignore condition following the first Attend condition, the brain responses between standard and deviant melodic patterns differed significantly from each other in Accurate subjects. The MMN amplitude at $100-150 \mathrm{~ms}$ after the deviant-tone onset was $-1.0 \mu \mathrm{V}$ in the second and $-1.2 \mu \mathrm{V}$ in the third condition $[t(7)=2.4$, $P<0.05$ and $t(7)=2.4, P<0.05$, respectively $]$. At $150-200$ $\mathrm{ms}$ after the deviant-tone onset the MMN amplitude was $-2.2 \mu \mathrm{V}$ in both the second and the third conditions $[t(7)=$ 4.1, $P<0.01$ and $t(7)=3.9, P<0.01$, respectively)].

In contrast, the brain responses of the Inaccurate subjects to standard and deviant melodic patterns did not differ significantly from one another even during the final part of the experiment (Fig. 1). This indicates that in these subjects, the discrimination task did not result in the development of a sufficiently accurate cortical memory trace representing the pattern (melodic contour) shared by the standard melodic patterns.

The MEG, with a high spatial resolution in determining the locus of neural activity and an excellent temporal resolution to follow the time course of this activity (Hämäläinen et al. 1993), was used additionally to locate the brain areas associated with the present sound change discrimination

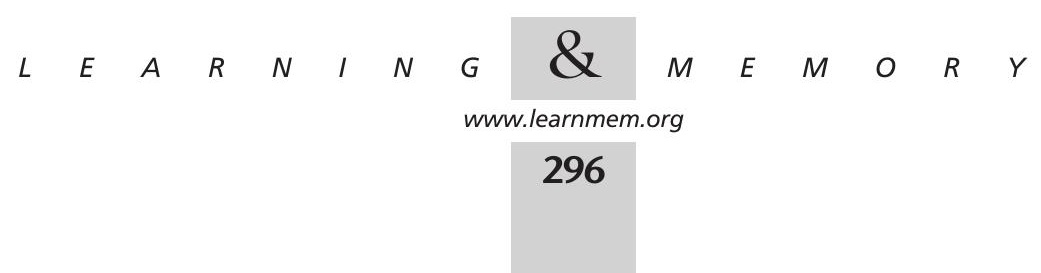



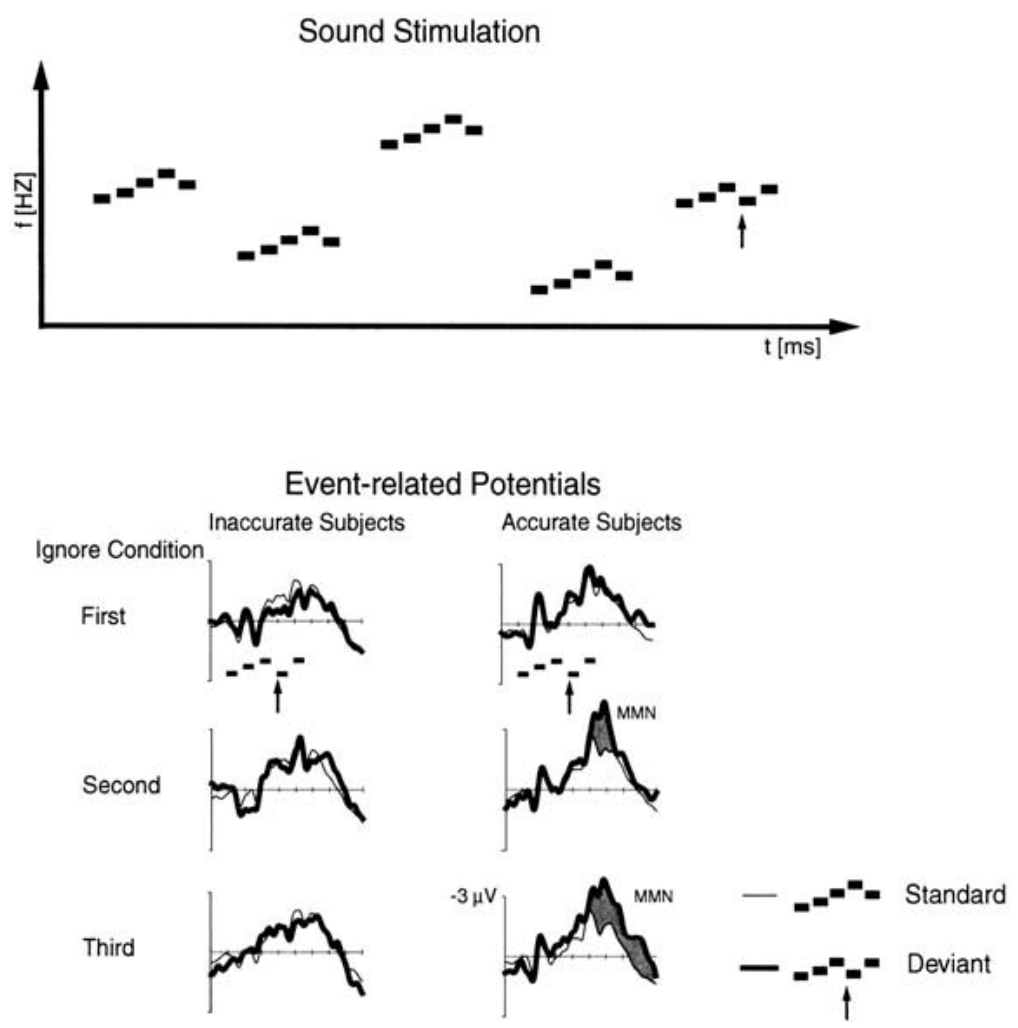

Figure 1 (Upper panel) Schematic illustration of the melodic patterns used in the present study. The arrow indicates the change in melodic pattern in infrequently presented deviant patterns. (Lower panel) Event-related potentials elicited by the standard (90\%; thin line) and the deviant (10\%; thick line) melodic patterns recorded at the Fz electrode. In the Accurate subjects, an MMN was elicited during the second and third Ignore conditions following the first Attend condition (right column). In the Inaccurate subjects, no MMN was observed at any phase of the experiment despite intermediate Attend conditions (left column).

(see Materials and Methods). The ECDs determined on the basis of the MEG data (see Materials and Methods) for the present MMN response were located in the auditory areas of the left and right temporal lobes (Fig. 2). Thus, these data indicate that the detection of a change in the melodic pattern occurred in the auditory cortex.

\section{DISCUSSION}

The goal of the present study was determining by the elec- tric and magnetic MMN recordings whether abstract rules about the melodic contour can be encoded automatically. Our paradigm allowed us to tease apart the contributions of short-term learning during an experimental session (facilitated by attentive discrimination) and long-term effects (caused by musical expertise) for such encoding.

In both EEG and MEG studies, deviant patterns elicited the MMN even when subjects did not listen attentively to the sounds. This demonstrates the existence of a highly

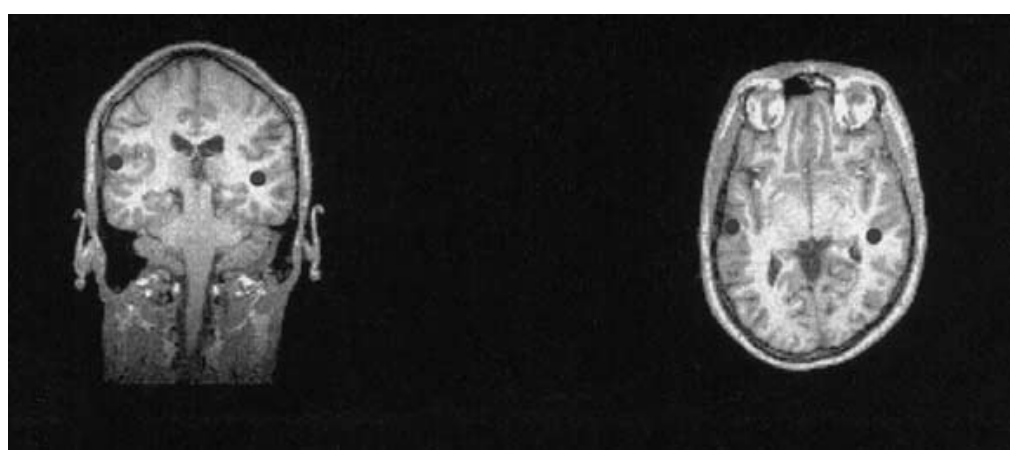

Figure 2 Average locations of the magnetic MMN responses (left: $3 \mathrm{Ss}$, right: $2 \mathrm{Ss}$ ) as modeled by the equivalent current source dipoles superimposed on a magnetic resonance imaging scan of one subject.

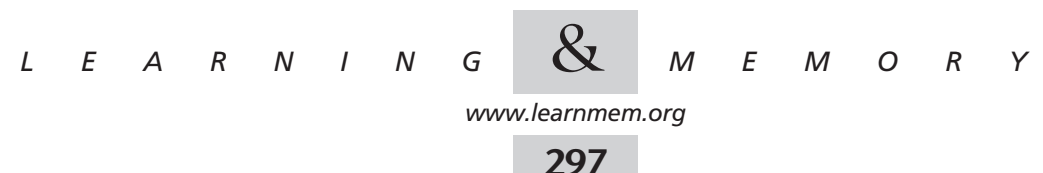


sophisticated system for pre-attentive invariance extraction. The present kind of invariance inherent in the stimulation is more abstract than those of previous studies (Saarinen et al. 1992; Tervaniemi et al. 1994; Paavilainen et al. 1998, 1999). Moreover, the MEG recordings showed that the ECDs of the MMN to violations in sound pattern are located in the auditory cortex. Although the present MEG data were obtained from only three subjects (in two of them in both hemispheres), they indicate that the memory traces underlying the discrimination between transposed melodic patterns with different contours were also located in the auditory cortex. Thus, in addition to being in agreement with previous MEG studies implying an auditory-cortex locus for the simple-feature sound representations (e.g., Hari et al. 1992; Alho et al. 1996; Levänen et al. 1996; Tervaniemi et al. 1999; for review, see Alho 1995), the present finding extends these results by indicating that abstract, invariant sound features are also represented in the auditory cortex.

Importantly, the brain responses to standard and deviant melodic patterns did not differ from each other during the first Ignore condition (Fig. 1). However, after the first Attend condition, during which the Accurate subjects learned to discriminate the melodic contours, a significant MMN response was elicited by deviant melodic contours in them. This indicates that some training was required to establish sufficiently accurate memory traces that would be accessible to the early auditory processing mechanisms for the automatic change detection to occur. Because of the complexity of the present stimulation, even the Accurate subjects had to listen to the sounds consciously before their cortical memory traces could develop for the abstract pattern; thereafter, they could classify automatically the patterns as same or different. This result agrees with previous studies in humans and animals, indicating that attention towards the critical sensory input facilitates neuronal learning (Singer 1982; Ahissair et al. 1992; Recanzone et al. 1992; Näätänen et al. 1993).

However, not all subjects gained equally from the training during the experimental session. The present inter-individual differences in readiness to discriminate transposed melodies could be explained by differences in long-term musical expertise. While all Accurate subjects were professional musicians, the group of Inaccurate subjects had five musicians in addition to the seven nonmusicians. Thus, none of the non-musicians learned the discrimination task, whereas most of the musicians did. It is noteworthy that the musicians belonging to the "Accurate" and "Inaccurate" groups differed remarkably from each other with regard to the type of their musical expertise. The musicians in the Inaccurate group had most of their training in classical music, in which the musical score is used regularly during learning and occasionally during public performance, as in orchestral and chamber music, for instance. In contrast, six out of the eight musicians in the Accurate group were engaged in a musical genre in which musical information is transferred from one musician to another by playing and singing (e.g., pop and jazz). Their performances often include improvisations. In other words, in their musical communication, they rely more on auditory information than visual (i.e., musical score). Thus, the subject's readiness to process attentively and pre-attentively highly complex musical information was not influenced merely by the presence or absence of expertise in music (musician vs. nonmusician), but also by the type of this expertise (Sloboda 1985; Deliege and Sloboda 1996).

In conclusion, the present results show that changes in an invariant sound pattern present in acoustically varying stimulation can be discriminated automatically by the human brain after perceptual learning during attentive listening has taken place. Perceptual learning results in the formation of a neural representation of the sound pattern that is generalized across the acoustically varying short melodic patterns. This formation occurs especially in musicians who perform music primarily without a score. Our magnetic recordings revealed that the automatic detection of pattern change occurs in the auditory cortex. This indicates that the abstract sound-pattern representations underlying this automatic pattern-recognition process are also located in the auditory cortex.

\section{MATERIALS AND METHODS}

\section{Stimuli}

Healthy adult subjects were presented with melodic patterns by the NeuroStim (Neurosoft, Inc.) software. The patterns consisted of five 50 -ms sinusoidal tones separated by 50 -ms silent intervals (Fig. 1). They were presented with 1200 -ms onset-to-onset intervals randomly at 12 frequency levels belonging to the Western musical scale. The lowest frequency in a pattern ranged between 330 and $523 \mathrm{~Hz}$ and the highest one between 622 and $989 \mathrm{~Hz}$. The majority of the patterns, the "standards", had a melodic contour of an inverted $\mathrm{U}$, whereas $10 \%$ of the patterns, the "deviants", had a different contour. To prevent contribution of new afferent (frequency-specific) neurons (Näätänen 1992) to the deviance-related activity under present interest, the deviants did not include any new frequencies; instead, their fourth frequency corresponded to that of the first frequency. In abstract terms, the standard pattern followed the rule ABCED, whereas the deviant followed the rule ABCAD, regardless of their frequency level. Thus the sound-pattern transpositions were exact, preserving the melody pattern without preserving the key.

\section{Subjects}

Twenty healthy subjects with normal hearing were studied (17-40 yrs, mean 26 yrs; six of the subjects were females). They were thoroughly interviewed after the experiment with regard to their musical background. Seven of them had no training in music, although two had learned to play a musical instrument on their own. Thirteen played one or several musical instruments professionally or were engaged in university-level education in music perfor-

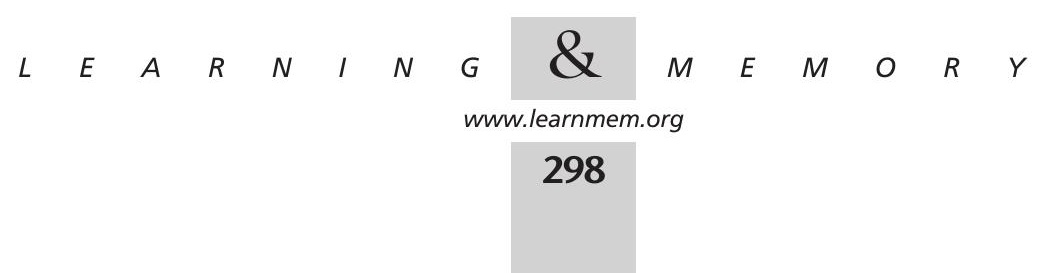


mance (mean age of starting the training was nine years). None of them had absolute pitch. Five subjects had received training in classical music whereas eight had studied jazz and pop music.

\section{EEG Recordings}

EEG was recorded (passband, $0.1-100 \mathrm{~Hz}$; sampling rate, $500 \mathrm{~Hz}$ ) with a 32-channel electrode cap (Lectron, Finland). In addition, horizontal eye movements were monitored with an EOG electrode at the right outer canthus and vertical eye movements with an electrode at Fpz. Both EEG and EOG were referenced to the nose. The EEG was divided into $1100-\mathrm{ms}$ epochs that were averaged separately for standard and deviant patterns. Responses elicited by a deviant pattern immediately following a deviant pattern were disregarded from further analysis; all the other epochs following deviant and standard pattern presentations were included. All epochs including voltage changes exceeding $\pm 75 \mu \mathrm{V}$ were rejected and frequencies above $20 \mathrm{~Hz}$ were filtered out. Difference waveforms were calculated by subtracting the averaged response to the standard stimuli from those to the deviant stimuli. Two-tailed $t$-tests were used to evaluate the statistical significance of the MMN amplitude at the $\mathrm{Fz}$ electrode in 50-ms segments from 100 to $400 \mathrm{~ms}$ from the onset of the deviant tone.

\section{Procedure}

The experiment consisted of three alternating presentations of Ignore and Attend conditions. In the Ignore conditions ( $24 \mathrm{~min}$ in duration, with 1200 melodic patterns), the subject watched a selfselected silent movie while being presented with the melodic patterns binaurally via headphones. The subject's electric brain responses were recorded during the Ignore conditions. In the Attend conditions (12 min each, with 600 melodic patterns), the subject was asked to press a response key on detecting a deviant melodic pattern. Responses $0-750 \mathrm{~ms}$ after the deviant tone onset were accepted as hits. The subjects were not given feedback about their performance.

\section{MEG Recordings}

Four subjects (a subgroup of those with accurate behavioral discrimination of the deviant pattern in the EEG study; see Results) were studied. The stimulation was identical to that in the EEG recordings. For practical reasons, however, there were only two Ignore conditions, separated by one Attend condition. The MEG was recorded in a magnetically shielded room (Euroshield Ltd.) in the BioMag Laboratory of the Helsinki University Central Hospital with a helmet-shaped 122-channel whole-head magnetometer (Neuromag Ltd.). The MEG epochs (passband, 0.1-100 Hz; sampling rate, $398 \mathrm{~Hz}$ ), starting $100 \mathrm{~ms}$ before and ending $1100 \mathrm{~ms}$ after each stimulus onset, were averaged on-line separately for standard and deviant stimuli. Horizontal and vertical eye movements were monitored with EOG electrodes placed above and below the left eye and lateral to the eyes. Epochs with an EOG deflection $>150 \mu \mathrm{V}$ or an MEG amplitude $>1500 \mathrm{fT} / \mathrm{cm}$ were rejected. The responses were filtered digitally with a passband of $0.5-20 \mathrm{~Hz}$.

One equivalent current dipole (ECD) for MMNm between 100 and $300 \mathrm{~ms}$ after deviant-tone onset was fitted separately for the left and right hemispheres using a fixed subset of 30 MEG channels over each auditory cortex; the spherical head model was used (Hämäläinen et al. 1993). The center of the model sphere was placed $45 \mathrm{~mm}$ above the origin of the coordinate system defined so that the $\mathrm{X}$-axis pointed from the left to the right preauricular point and the $\mathrm{Y}$-axis was perpendicular to the $\mathrm{X}$-axis and passed through the nasion; the z-axis pointed upwards. Each ECD was determined so that it explained optimally the recorded magnetic field and had the largest dipole moment between 100 and $300 \mathrm{~ms}$ after the onset of the deviance. All ECDs accepted for analysis explained $>70 \%$ of the measured magnetic field, were oriented as expected on the basis of the corresponding electric component (i.e., MMNm ECD producing negativity at the frontal and central scalp areas), and were at least $30 \mathrm{~mm}$ from the mid-sagittal plane. At this stage, the data from one subject were rejected because of atypical dipole orientation. In addition, for one subject, only the ECD in the left hemisphere could be determined successfully. An MRI scan from one subject was used to display the average ECD loci (see above).

\section{ACKNOWLEDGMENTS}

We thank Dr. Pentti Laurinen and Dr. Teija Kujala for their constructive comments on an earlier version of the manuscript and $\mathrm{Mr}$. Ville Mäkinen for assistance in MEG recordings and MRI scanning. This study was supported by the Academy of Finland and by the Deutsche Akademische Austauschdienst.

The publication costs of this article were defrayed in part by payment of page charges. This article must therefore be hereby marked "advertisement" in accordance with 18 USC section 1734 solely to indicate this fact.

\section{REFERENCES}

Ahissar, E., Vaadia, E., Ahissar, M., Bergman, H., Arieli, A., and Abeles, M. 1992. Dependence of cortical plasticity on correlated activity of single neurons and on behavioral context. Science 257: 1412-1415.

Alain, C., Woods, D.L., and Ogawa. K.H. 1994. Brain indices of automatic pattern processing. NeuroReport 6: 140-144.

Alho, K. 1995. Cerebral generators of mismatch negativity (MMN) and its magnetic counterpart (MMNm) elicited by sound changes. Ear Hear. 16: $38-51$.

Alho, K., Tervaniemi, M., Huotilainen, M., Lavikainen, J., Tiitinen, H., Ilmoniemi, R.J., Knuutila, J., and Näätänen, R. 1996. Processing of complex sounds in the human auditory cortex as revealed by magnetic brain responses. Psychophysiology 33: 369-375.

Deliege, I. and Sloboda, J.A. (eds.). 1996. Musical Beginnings - Origins and Development of Musical Competence. Oxford University Press, Oxford.

Hämäläinen, M., Hari, R., Ilmoniemi, R.J., Knuutila, J., and Lounasmaa, O.V. 1993. Magnetoencephalography-theory, instrumentation, and applications to noninvasive studies of the working human brain. Rev. Mod. Phys. 65: 413-497.

Hari, R., Rif, J. Tiihonen, J., and Sams, M. 1992. Neuromagnetic mismatch fields to single and paired tones. Electroencephalogr. Clin. Neurophysiol. 82: 152-154

Kraus, N., McGee, T.J., Carrell, T.D., Zecker, S.G, Nicol, T.G., and Koch, D.B. 1996. Auditory neurophysiologic responses and discrimination deficits in children with learning problems. Science 273: 971-973.

Levänen, S., Ahonen, A., Hari, R., McEvoy, L., and Sams, M. 1996. Deviant auditory stimuli activate human left and right auditory cortex differently. Cereb. Cortex 6: 288-296.

Menning, H., Roberts, L.E., and Pantev, C. 2000. Plastic changes in the auditory cortex induced by intensive frequency discrimination training. Neuroreport 11: 817-822.

Näätänen, R. 1992. Attention and Brain Function. Lawrence Erlbaum, Hillsdale, NJ

Näätänen, R. 2001. The perception of speech sounds by the human brain as reflected by the mismatch negativity (MMN) and its magnetic equivalent (MMNm). Psychophysiology 38: 1-21.

Näätänen, R., Lehtokoski. A., Lennes, M., Cheour, M., Huotilainen, M., Iivonen, A., Vainio, M., Alku, P., Ilmoniemi, R.J., Luuk, A., et al. 1997. Language-specific phoneme representations revealed by electric and magnetic brain responses. Nature 385: 432-434.

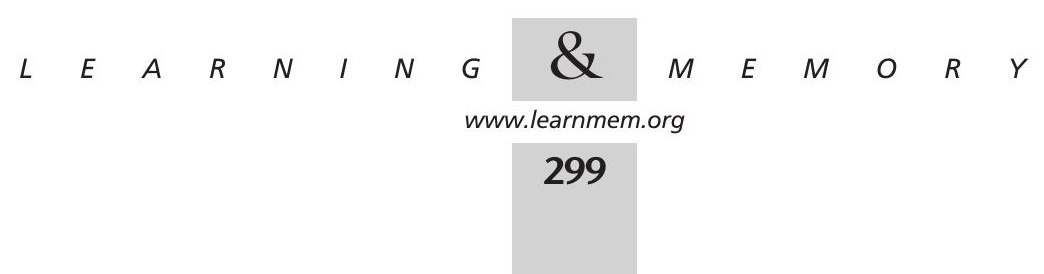


Näätänen, R., Schröger, E., Karakas, S., Tervaniemi, M., and Paavilainen, P. 1993. Development of a memory trace for a complex sound in the human brain. Neuroreport 4: 503-506.

Näätänen, R. and Winkler, I. 1999. The concept of auditory stimulus representation in cognitive neuroscience. Psychol. Bull. 125: 826-859.

Paavilainen, P., Jaramillo, M., and Näätänen, R. 1998. Binaural information can converge in abstract memory traces. Psychophysiology 35: $483-487$

Paavilainen, P., Jaramillo, M., Näätänen, R., and Winkler, I. 1999. Neuronal populations in the human brain extracting invariant relationships from acoustic variance. Neurosci. Lett. 265: 179-182.

Recanzone, G.H., Merzenich, M.M., Jenkins, K.A., Grajski, W.M., and Dinse, H.R. 1992. Topographic reorganization of the hand representation in cortical area $3 \mathrm{~b}$ of owl monkeys trained in a frequency-discrimination task. J. Neurophysiol. 67: 1031-1036.

Rugg, M. D. and Coles, M.G.H. (eds.) 1995. Electrophysiology of Mind. Oxford University Press, Oxford

Saarinen, J., Paavilainen, P., Schröger, E., Tervaniemi, M., and Näätänen, R. 1992. Representation of abstract attributes of auditory stimuli in human brain. Neuroreport 3: 1149-1151.

Schröger, E. 2000. Top-down effects on auditory sensory memory processing. In Contributions to Psychological Acoustics, Results of the Eighth Oldenburg Symposium on Psychological Acoustics (eds. A. Schick, M. Meis, and M. Reckhardt), pp. 337-353. Bibliotheks- und Informationssystem der Universität Oldenburg, Oldenburg.

Schröger, E., Tervaniemi, M., Wolff, C., and Näätänen, R. 1996. Preattentive periodicity detection in auditory patterns as governed by time and intensity information. Brain Res. Cogn. Brain Res. 4: 145-148.

Singer, W. 1982. The role of attention in developmental plasticity. Hum. Neurobiol. 1: 41-43.

Sloboda, J.A. 1985. The Musical Mind. New York: Oxford University Press, New York.

Tervaniemi M., Ilvonen, T., Karma, K., Alho, K., and Näätänen, R. 1997. The musical brain: Brain waves reveal the neurophysiological basis of musicality in human subjects. Neurosci. Lett. 226: 1-4.

Tervaniemi, M., Kujala, A., Alho, K., Virtanen, J., Ilmoniemi, R.J., and Näätänen, R. 1999. Functional specialization of the human auditory cortex in processing phonetic and musical sounds: A magnetoencephalographic (MEG) study. Neuroimage 9: 330-336.

Tervaniemi, M., Maury, S., and Näätänen, R. 1994. Neural representations of abstract features in the human brain as reflected by the mismatch negativity. Neuroreport 5: 844-846.

Tiitinen, H., May, P., Reinikainen, K., and Näätänen, R. 1994. Attentive novelty detection in humans is governed by pre-attentive sensory memory. Nature 372: 90-92.

Tremblay, K., Kraus, N., and McGee, T. 1998. The time course of auditory perceptual learning: Neurophysiological changes during speech-sound training. Neuroreport 9: 3557-3560.

Wolff, C. and Schröger, E. 2001. Activation of the auditory pre-attentive change detection system by tone repetitions with fast stimulation rate. Brain Res. Cogn. Brain Res. 10: 323-327.

Received February 7, 2001; accepted in revised form July 10, 2001.

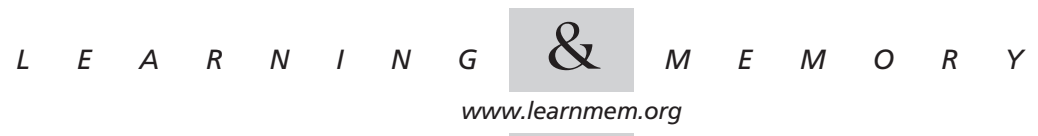




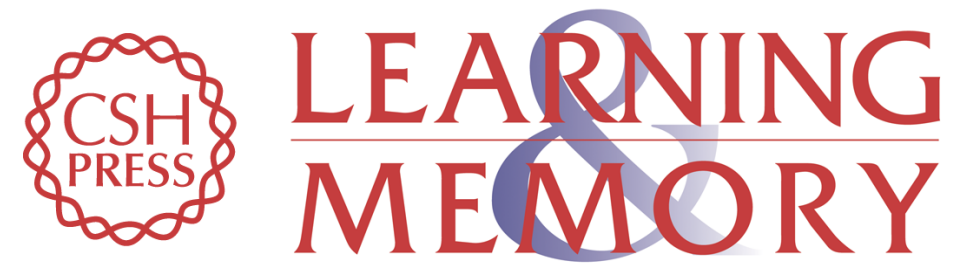

\section{Superior Formation of Cortical Memory Traces for Melodic Patterns in Musicians}

Mari Tervaniemi, Mika Rytkönen, Erich Schröger, et al.

Learn. Mem. 2001, 8:

Access the most recent version at doi:10.1101//m.39501

References This article cites 25 articles, 2 of which can be accessed free at:

http://learnmem.cshlp.org/content/8/5/295.full.html\#ref-list-1

License

Email Alerting Receive free email alerts when new articles cite this article - sign up in the box at the Service top right corner of the article or click here. 